\title{
Beta cell adaptation in pregnancy: a major difference between humans and rodents?
}

\author{
M. Genevay $\cdot$ H. Pontes $\cdot$ P. Meda
}

Received: 11 June 2010 / Accepted: 15 June 2010 /Published online: 10 July 2010

(C) Springer-Verlag 2010

Keywords Beta cell adaptation $\cdot$ Beta cell apoptosis $\cdot$ Beta cell mass $\cdot$ Beta cell proliferation $\cdot$ CX36 $\cdot$ Human beta cells $\cdot$ Islet neogenesis $\cdot$ Pregnancy $\cdot$ Prolactin

Increasing evidence demonstrates that the insulin-producing beta cells can dynamically adapt their size, number and function in response to a variety of experimental and pathological conditions. Whether this dynamic adaptation also takes place under physiological conditions is less clear, with the notable exception of pregnancy $[1,2]$. Under this condition, it has long been known that rodents undergo a rapid and substantial expansion of beta cell mass [3-5] due to increased beta cell size (hypertrophy) and replication (hyperplasia) [4], without detectable evidence of islet neogenesis [5]. These changes are induced by prolactin, placental lactogen and growth hormone, whose receptors are upregulated in beta cells after two-thirds of the gestational duration $[1,6]$. They are also rapidly reversed at about the time of delivery, due to progesterone-controlled activation of beta cell apoptosis [7]. Recent studies have implicated selected genes controlling beta cell replication, survival and apoptosis in these changes [8-10]. In rodents, the changes in beta cell mass (about three- to fivefold) cannot alone account for those in insulin output (about eightfold), implicating a further functional improvement [1]. Thus, serum insulin increases by $\sim 75 \%$ due to increased

\section{Genevay}

Division of Pathology, Geneva University Hospital,

Geneva, Switzerland

H. Pontes $\cdot$ P. Meda $(\square)$

Department of Cell Physiology and Metabolism,

University of Geneva, School of Medicine, CMU,

1 rue Michel Servet,

CH-1211 Geneva 4, Switzerland

e-mail: Paolo.Meda@unige.ch glucose-stimulated insulin secretion, and this happens despite a $25 \%$ reduction in plasma glucose $[5,11,12]$. The increase in glucose-stimulated insulin secretion is mostly due to a significant decrease in the threshold for glucose stimulation $[1,12,13]$, possibly as a result of higher levels of GLUT2, glucokinase and beta cell to beta cell coupling $[13,14]$.

It has also long been known that the progressive development of insulin resistance during human pregnancy increases the metabolic demand on beta cells, as evidenced by increased insulin secretion [11]. Due to the difficulty of obtaining pancreas from pregnant women, the adaptive mechanism underlying this change remains poorly investigated. However, islet enlargement, attributed to increased beta cell proliferation and decreased beta cell apoptosis, has been reported in a limited number of human samples [15], suggesting that similar mechanisms are responsible for beta cell adaptation in rodent and human pregnancy.

This tentative conclusion needs to be critically revisited in view of recent data. First, the profile of genes that control beta cell proliferation differs in rodents and humans $[2,16]$. Second, several studies have now documented that, in contrast with rodents, human beta cells do not proliferate under most conditions, probably due to an age-dependent epigenetic regulation of specific genes [17]. Moreover, a new pathology study has now raised the possibility that the adaptation of human beta cells to pregnancy may be significantly less extensive than in rodents and also due to a quite different mechanism [18]. Thus, in this issue of Diabetologia, Butler et al. [18] document that the volume density of beta cells was increased by only $\sim 1.4$-fold in human pregnancy due to increased numbers of small islets, and not to beta cell size. These changes were associated with increased numbers of scattered and duct-associated beta cells, in the absence of detectable changes in beta cell replication and apoptosis. Thus, two studies of human samples $[15,18]$ concur in showing that beta cells increase as a function of the increasing gestational demand, but they 
significantly differ in their evaluation (1) of the extent of this adaptation, and (2) of the mechanisms responsible for it.

Several factors may account for these differences. First, differences in the populations studied. Thus, whereas one study only evaluated control women who had died in car accidents [15], the other also included women with inflammatory diseases [18], which could potentially have affected insulin resistance and/or altered the residual beta cell mass. Second, the method used to track beta cells, which was histochemical staining in one study [15] and insulin immunostaining in the other [18]. Importantly, when assessing the validity of these differences, the limited number of cases investigated in both studies should be kept in mind. Using the mean and SE values indicated in the study by Butler et al. [18], the probability of finding a statistically significant difference at $p=0.05$ can be evaluated to provide a power of only $50 \%$ to $60 \%$. Significantly larger numbers of control and pregnant women would need to be compared to reach more powerful conclusions, a limitation inherent to most pathology studies on rare specimens.

With this caveat in mind, the new study [18] nevertheless suggests that rodent and human beta cells may adapt differently to pregnancy. First, the extent of this adaptation may be smaller in humans than in rodents. Second, the mechanism responsible for this adaptation involves increased replication and decreased apoptosis in rodents, but possibly islet neogenesis in humans (Fig. 1). It is worth noting that whereas all animal studies were conducted in young animals, when the epigenetic changes that severely restrict beta cell replication have not yet occurred [17], this is not the case in humans, providing a possible clue as to why no replication change was detected in the latter. In addition, no significant change in beta cell apoptosis was detected, in agreement with the low rate of this event in non-pregnant humans [5]. Further, the new study [18] provides indirect evidence that the adaptation observed in humans may result from islet neogenesis. This finding is relevant, inasmuch as the occurrence of islet neogenesis is disputed in adult rodents $[5,19]$. The question of whether the contribution of this process is more important in humans [20] requires the identification of a validated marker for islet neogenesis that could be applied to the study of human samples. At any rate, the Butler et al. paper adds to the increasing literature indicating that rodent and human islets differ in several, though not all respects [21]. Studies of other species may help clarify whether these differences are dispensable evolutionary modifications, whereas similarities may reflect obligatory characteristics.

It has been previously noted that the changes in beta cell mass observed in rodent pregnancy cannot fully account for the larger increase in insulin secretion, whereby normal beta cells compensate for the pregnancy-related increase in
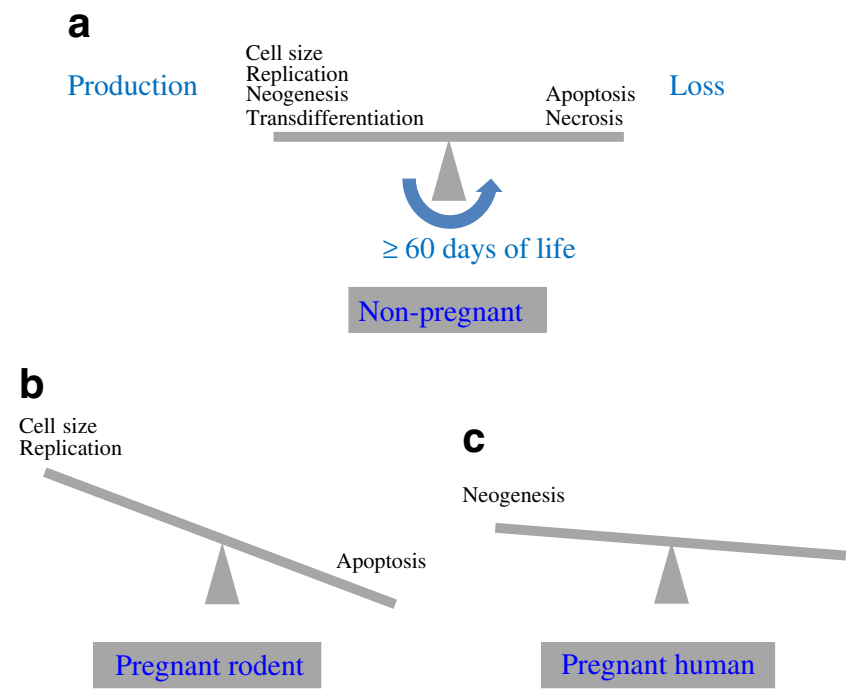

Fig. 1 Beta cell mass may be differentially controlled in rodent and human pregnancy. a The mass of beta cells results from the balance between mechanisms that produce (cell size, replication, neogenesis and transdifferentiation) and reduce (apoptosis and necrosis) cell size and number. b During pregnancy, rodents increase beta cell mass by three- to fivefold by increasing beta cell size (hypertrophy) and replication (hyperplasia), while reducing beta cell apoptosis. c In humans, these changes may be only 1.5 -fold and due to islet neogenesis

insulin resistance [1]. This implies that in the healthy animal, beta cell function is enhanced. The mechanism of this functional adaptation has not been fully elucidated, even though proteins and mechanisms that could conceivably account for the enhanced beta cell function have been identified [12-14]. The relative contribution of these changes can now be experimentally tested, using mice invalidated for specific beta cell proteins or mice overexpressing them. The Butler study [18] suggests that in humans, too, increased beta cell function, which is also supported by increased levels of circulating C-peptide during pregnancy in women with type 1 diabetes [22], may be larger than the increase of beta cell mass. If the underlying mechanism is similar in rodents and humans, future studies should investigate beta cell proteins that are expressed in both species and involved in the control of insulin expression, glucose-induced insulin secretion and beta cell survival. Among the candidates, the gap junction protein, connexin-36, may deserve attention [1], as it is present in rodent and human beta cells [21,23], is linked to insulin expression in both species [21,23], and is required for proper glucose-induced insulin secretion [23, 24]. The direct exchanges of cytosolic molecules that this protein mediates between beta cells [21, 23, 24] are increased during rodent pregnancy [14].

Understanding the mechanisms that mediate the functional adaptation of beta cells to pregnancy will explain how insufficient adaptation leads to gestational diabetes 


\section{Some suggestions for future research}

- Explore additional human samples from different populations to validate the mechanism of beta cell adaptation

- Explore non-diabetic obese humans to assess whether beta cells adapt as in pregnancy

- Study beta cell adaptation in aged rodents, with specific regard to islet neogenesis

- Study beta cell adaptation in other animal species

- Explore whether beta cell adaptation is altered in mice invalidated for key beta cell proteins (GLUT2, glucokinase, connexin-36, etc.)

- Investigate the mechanisms of functional beta cell adaptation in isolated islets and insulinproducing lines of rodent and human origin

- Search for factors promoting beta cell survival, function or expansion at the beginning of rodent pregnancy

- Explore whether any of these factors improve the in vitro differentiation or expansion of insulin-producing cells

- Validate the effects of genes modulated during pregnancy ( $c M y c$ [also known as Myc], menin, Ki67 [also known as Mki67], Thp1/2, Birc5, caspase 3, Cish, Socs2, etc.) on beta cell replication, survival, apoptosis and function

[25]. It could also provide novel insights into how to expand the glucose-sensitive insulin-producing cells that are needed for implementation of cell therapy in patients with diabetes. Rodent and human studies indicate that the required beta cell changes occur in the first third of pregnancy $[2,26]$, whereas insulin resistance is established in the last third of pregnancy $[26,27]$. Thus, the factor(s) and mechanism(s) promoting beta cell expansion and survival may be advantageously searched for at the beginning of gestation.

In summary, animal and human studies demonstrate that beta cells adapt to pregnancy by changing their mass and, to an even greater degree, their function. They suggest, however, that the mechanism responsible for the structural beta cell adaptation may differ in the two species (Fig. 1). This conclusion remains tentative, due to the difficulty of assessing large numbers of women and to other limitations of retrospective autopsy studies [15, 18], stressing the importance of further developments in this area. Until then, conditions inducing beta cell expansion in rodents should not be assumed to apply to humans. Further research efforts are now needed (see textbox) to address this question and to better define the functional mechanisms of beta cell adaptation. The results can be expected to lead to the identification of new therapeutic targets, which may be instrumental for a therapy of diabetes.

Acknowledgements Our work is supported by grants from the Swiss National Science Foundation (310000-122423, 310000-109402, CR32I3 129987), the Juvenile Diabetes Research Foundation (1-2007158), the Novartis Consumer Health Foundation and the European Union (BETAIMAGE 222980; IMIDIA, C2008-T7).
Duality of interest The authors declare that there is no duality of interest associated with this manuscript.

\section{References}

1. Sorenson RL, Brelje TC (1997) Adaptation of islets of Langerhans to pregnancy: beta-cell growth, enhanced insulin secretion and the role of lactogenic hormones. Horm Metab Res 29:301-307

2. Rieck S, Kaestner KH (2010) Expansion of beta-cell mass in response to pregnancy. Trends Endocrinol Metab 21:151-158

3. Hellmann B (1960) The islets of Langerhans in the rat during pregnancy and lactation, with special reference to the changes in the B/A cell ratio. Acta Obstet Gynecol Scand 39:331-342

4. Van Assche FA (1974) Quantitative morphologic and histoenzymatic study of the endocrine pancreas in nonpregnant and pregnant rats. Am J Obstet Gynecol 118:39-41

5. Parsons JA, Brelje TC, Sorenson RL (1992) Adaptation of islets of Langerhans to pregnancy: increased islet cell proliferation and insulin secretion correlates with the onset of placental lactogen secretion. Endocrinology 130:1459-1466

6. Møldrup A, Petersen ED, Nielsen JH (1993) Effects of sex and pregnancy hormones on growth hormone and prolactin receptor gene expression in insulin-producing cells. Endocrinology 133:1165-1172

7. Scaglia L, Smith FE, Bonner-Weir S (1995) Apoptosis contributes to the involution of beta cell mass in the post partum rat pancreas. Endocrinology 136:5461-5468

8. Jiang Y, Nishimura W, Devor-Henneman D et al (2008) Postnatal expansion of the pancreatic $\beta$-cell mass is dependent on survivin. Diabetes 57:2718-2727

9. Karnik SK, Chen H, McLean GW et al (2007) Menin controls growth of pancreatic beta-cells in pregnant mice and promotes gestational diabetes mellitus. Science 318:806-809

10. Rieck S, White P, Schug J et al (2009) The transcriptional response of the islet to pregnancy in mice. Mol Endocrinol 23:1702-1712 
11. Costrini NV, Kalkhoff RK (1991) Relative effects of pregnancy, estradiol and progesterone on plasma insulin and pancreatic islet content. J Clin Invest 50:992-999

12. Green IC, Taylor KW (1972) Effects of pregnancy in the rat on the size and insulin secretory response of the islets of Langerhans. J Endocrinol 54:317-325

13. Weinhaus AJ, Stout LE, Bhagroo NV, Brelje TC, Sorenson RL (2007) Regulation of glucokinase in pancreatic islets by prolactin: a mechanism for increasing glucose-stimulated insulin secretion during pregnancy. J Endocrinol 193:367-381

14. Sorenson RL, Brelje TC, Hegre OD, Marshall S, Anaya P, Sheridan JD (1987) Prolactin (in vitro) decreases the glucose stimulation threshold, enhances insulin secretion, and increases dye coupling among islet B cells. Endocrinology 121:14471453

15. Van Assche FA, Aerts L, De Prins F (1978) A morphological study of the endocrine pancreas in human pregnancy. Br J Obstet Gynaecol 85:818-820

16. Fiaschi-Taesch N, Bigatel TA, Sicari B et al (2009) Survey of the human pancreatic beta-cell $\mathrm{G} 1 / \mathrm{S}$ proteome reveals a potential therapeutic role for cdk- 6 and cyclin D1 in enhancing human betacell replication and function in vivo. Diabetes 58:882-893

17. Tschen SI, Dhawan S, Gurlo T, Bhushan A (2009) Age-dependent decline in beta cell proliferation restricts the capacity of beta cell regeneration in mice. Diabetes 58:1312-1320

18. Butler AE, Cao-Minh L, Galasso R et al. (2010) Adaptive changes in pancreatic beta cell fractional area and beta cell turnover in human pregnancy. Diabetologia. doi:10.1007/s00125-010-1809-6

19. Xu X, D'Hoker J, Stangé G et al (2008) Beta cells can be generated from endogenous progenitors in injured adult mouse pancreas. Cell 132:197-207
20. Klöppel G, Bommer G, Commandeur G, Heitz P (1978) The endocrine pancreas in chronic pancreatitis. Immunocytochemical and ultrastructural studies. Virchows Arch A Pathol Anat Histol 377:157-174

21. Serre-Beinier V, Bosco D, Zulianello L et al (2009) Cx36 makes channels coupling human pancreatic beta-cells, and correlates with insulin expression. Hum Mol Genet 18:428-439

22. Nielsen LR, Rehfeld JF, Pedersen-Bjergaard U, Damm P, Mathiesen ER (2009) Pregnancy-induced rise in serum Cpeptide concentrations in women with type 1 diabetes. Diabetes Care 32:1052-1057

23. Carvalho CP, Barbosa HC, Britan A et al (2010) Beta cell coupling and connexin expression change during the functional maturation of rat pancreatic islets. Diabetologia 53:1428-1437

24. Ravier MA, Güldenagel M, Charollais A et al (2005) Loss of connexin36 channels alters beta-cell coupling, islet synchronization of glucose-induced $\mathrm{Ca}^{2+}$ and insulin oscillations, and basal insulin release. Diabetes 54:1798-1807

25. Devlieger R, Casteels K, van Assche FA (2008) Reduced adaptation of the pancreatic B cells during pregnancy is the major causal factor for gestational diabetes: current knowledge and metabolic effects on the offspring. Acta Obstet Gynecol Scand 87:1266-1270

26. Catalano PM, Tyzbir ED, Roman NM, Amini SB, Sims EA (1991) Longitudinal changes in insulin release and insulin resistance in nonobese pregnant women. Am J Obstet Gynecol $165: 1667-1672$

27. Buchanan TA, Metzger BE, Freinkel N, Bergman RN (1990) Insulin sensitivity and B cell responsiveness to glucose during late pregnancy in lean and moderately obese women with normal glucose tolerance or mild gestational diabetes. Am J Obstet Gynecol 162:1008-1014 